\title{
Haemodynamic results of replacement of mitral and aortic valves with autologous fascia lata prostheses
}

\author{
P. H. TALAVLIKAR, P.R. WALBAUM, and A. H. KITCHIN \\ Department of Cardiology, Western General Hospital, Edinburgh
}

\begin{abstract}
Twelve patients undergoing aortic and 28 undergoing mitral valve replacement with autologous fascia lata valves were studied before and six months after surgery. One aortic and 10 mitral valves were found to be significantly incompetent. Of the incompetent mitral valves, two appeared to have perivalvular leaks. Six of the remainder were associated with abnormal ventricular filling patterns. Valve failure was much less common when the design was modified to provide a loose cusp structure; out of 12 such valves none was incompetent. Transvalvular gradients persist with fascial valves though they are lower than with most mechanical prostheses. Ventricular function was greatly improved in successful aortic replacement but remained impaired in the case of mitral replacement. Valve failure appeared to be associated with, or accelerated by, haemodynamic stress rather than due to inevitable degenerative pathological processes.
\end{abstract}

Prosthetic heart valves carry a considerable rate of subsequent mortality and morbidity from thrombo-embolism, haemolysis, and mechanical failure and a considerable incidence also of haemorrhagic complications from anticoagulant therapy. Starr has reported an incidence of thrombo-embolism ranging from $32 \%$ in the earlier model 1000 aortic valve to $9 \%$ in the model 2300 , and in the mitral replacements $56 \%$ in the earlier model 6000 to $13 \%$ in model 6300 (Hodam, Starr, Herr, and Pierie, 1969). Similar rates have been reported by other authors (Duvoisin et al., 1968; Rees et al., 1970; Barclay et al., 1972). Figure 1 shows postoperative survival rates over an eight-year period for 277 patients with Starr valve replacements. The operative mortality was $20 \%$. (a)

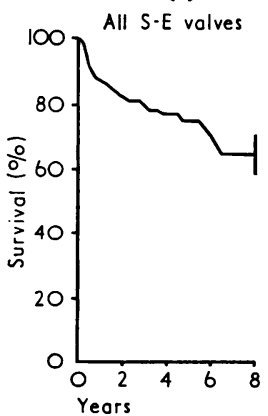

(b)

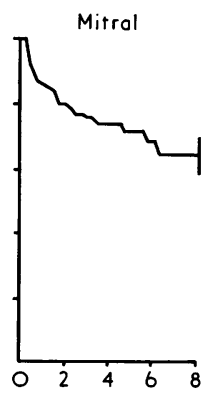

(c)

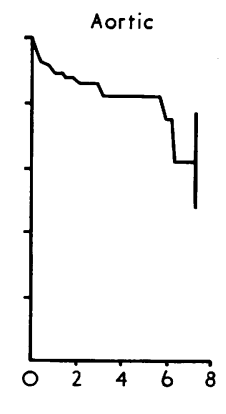

FG. 1. Eight-year survival rates in patients with Starr Edwards prostheses: (a) all patients, (b) single mitral, and (c) single aortic valves. Standard error of the mean is shown.
Hopes of improved performance from autologous fascia lata valves (Senning, 1967; Ionescu et al., 1970a ; Gerbode, 1970 ; Gonzalez-Lavin, Geens, and Ross, 1970 ; Gonzalez-Lavin and Ross, 1971) have been based on two factors-the strong yet pliant nature of the material used and the cusp structure of the valve simulating that of the natural semilunar valves and allowing an unobstructed axial stream through the valve.

Initial favourable reports following insertion of these valves in the aortic and mitral positions were followed by increasing numbers of valve failures. The most disquieting feature has been the high reported incidence of serious regurgitation occurring as a result of shrinkage and thickening of the valve cusps, particularly in the tricuspid and mitral positions. In 78 patients operated on by Ross (Ross, Gonzalez-Lavin, and Dalichau, 1972) for mitral replacement in a two-year period, $13 \%$ had mild and $14 \%$ moderate or severe regurgitation. Typically, thickening and rigidity of the cusps resulted in incompetence and Ross has now abandoned the use of fascial valves in the belief that long-term failure is highly probable (McEnany, Ross, and Yates, 1972).

The question of the cause of valve failure is not yet settled. It could reflect a progressive and inevitable tissue reaction to the presence of the fascia itself or a change in the physical properties of the dead fascial material with time. On the other hand, the changes could reflect haemo. dynamic factors stressing and ultimately destroying unfavourably designed or positioned valves. 
There is on the one hand evidence of consistent pathological changes reported in valves removed at necropsy or reoperation. These, however, are valves which have failed. In favour of the haemodynamic view, there is the widely differing experience of failure in different centres, and the strikingly different incidence of failures in the aortic from the mitral position, which is haemodynamically quite different.

\section{T A B LE I}

FASCIA LATA VALVE REPLACEMENTS

\begin{tabular}{|c|c|c|c|c|c|}
\hline & Mitral & Aortic & Double & Triple & Total \\
\hline $\begin{array}{cc}\text { Total number } & \ldots \\
\text { Male } & \ldots\end{array}$ & $\begin{array}{l}39 \\
10 \\
29\end{array}$ & $\begin{array}{l}36 \\
26 \\
10\end{array}$ & $\begin{array}{r}13 \\
7 \\
6\end{array}$ & $\begin{array}{l}2 \\
0 \\
2\end{array}$ & $\begin{array}{l}90 \\
43 \\
47\end{array}$ \\
\hline $\begin{array}{c}\text { Age under } 30 \text { yr } \\
30-50 \text { yr } \\
\text { Over } 50 \text { yr }\end{array}$ & $\begin{array}{r}0 \\
19 \\
20\end{array}$ & $\begin{array}{r}2 \\
14 \\
20\end{array}$ & $\begin{array}{l}1 \\
9 \\
3\end{array}$ & $\begin{array}{l}0 \\
2 \\
0\end{array}$ & $\begin{array}{r}3 \\
44 \\
43\end{array}$ \\
\hline $\begin{array}{l}\text { Previous valvotomy } \\
\text { Previous open-heart } \\
\text { operation }\end{array}$ & $\begin{array}{r}23 \\
4\end{array}$ & $\begin{array}{l}3 \\
5\end{array}$ & $\begin{array}{l}3 \\
3\end{array}$ & $\begin{array}{l}2 \\
0\end{array}$ & $\begin{array}{l}31 \\
12\end{array}$ \\
\hline
\end{tabular}

From this hospital 90 patients have had autologous fascial valve replacement in the past two years (Table I). The valves were constructed on Dacron-covered titanium frames as described by Ionescu et al. (1970b). Insufficient time has elapsed to compare long-term survival and complication rates with those in patients with Starr Edwards prostheses. We have, however, undertaken haemodynamic investigation in as many as possible of the survivors of operation six months after surgery with the following aims:

(1) to compare postoperative with preoperative haemodynamic measurements ;

(2) to find the relative prevalence and severity of valve regurgitation $(a)$ in the aortic valves and $(b)$ in the mitral valves;

(3) in those valves which were found to be competent, to compare the haemodynamic characterization of the valve with that reported with Starr Edwards prostheses;

(4) to compare with the original model of mitral fascial prosthesis a modified design with looser, horizontally lengthened cusps. This modification was introduced when it became apparent that the original design gave a high incidence of valve failure. It consisted in lengthening and widening slightly the strip of fascia lata used in making the valves (Table II). The effect of this was to lengthen the free margin of each cusp and to deepen the cusp at the midpoint of its length ;
(5) to identify, if possible, any haemodynamic factors common to those valves which were found to be incompetent.

T A B L E II

DIMENSIONS OF FASCIAL STRIP $(\mathrm{mm})$

\begin{tabular}{c|c|c}
\hline $\begin{array}{c}\text { Supporting Frame } \\
\text { Diameter (mm) }\end{array}$ & $\begin{array}{c}\text { Type 1 } \\
\text { (Ionescu et al., 1970a) }\end{array}$ & Type 2 \\
\hline 16 & $72 \times 15$ & $82 \times 18$ \\
18 & $78 \times 16$ & $94 \times 20$ \\
20 & $84 \times 18$ & $100 \times 22$ \\
22 & $91 \times 21$ & $104 \times 23$ \\
24 & $97 \times 22$ & $110 \times 25$ \\
26 & $104 \times 23$ & $116 \times 26$ \\
\hline
\end{tabular}

\section{PATIENTS AND METHODS}

There were 30 survivors of 39 mitral and 32 survivors of 36 aortic replacements. There were also nine survivors of 15 multiple valve replacements. There were four subsequent deaths in the mitral and three in the aortic series. The prevalence of murmurs postoperatively in the patients with single valves is shown

T A B L E I I I

POSTOPERATIVE MURMURS

\begin{tabular}{|c|c|c|c|c|c|}
\hline \multirow{2}{*}{\multicolumn{2}{|c|}{ Valve Replaced }} & \multirow{2}{*}{ No. } & \multicolumn{3}{|c|}{ Murmurs } \\
\hline & & & None & Systolic & Diastolic \\
\hline $\begin{array}{cc}\text { Mitral } & \\
\text { Type } & 1 \\
\text { Type } & \ldots \\
\text { Aortic } & \ldots\end{array}$ & $\begin{array}{l}\ldots \\
\cdots \\
\ldots\end{array}$ & $\begin{array}{l}18 \\
12 \\
32\end{array}$ & $\begin{array}{l}2 \\
3 \\
0\end{array}$ & $\begin{array}{r}11 \\
1 \\
32\end{array}$ & $\begin{array}{l}9 \\
9 \\
4\end{array}$ \\
\hline
\end{tabular}

in Table III. Thirty-five paitients with single and five with double replacements have been studied haemodynamically. All of these patients had preoperative catheterization and angiocardiography. The postoperative studies were carried out in the same manner six months after surgery. There were no complications following the repeat investigations.

T A B LE IV

FASCIAL PROSTHETIC VALVES

\begin{tabular}{|c|c|c|c|c|c|}
\hline & & & Studied & Competent & Leaking \\
\hline $\begin{array}{c}\text { Aortic } \ldots \\
\text { Mitral } \\
\text { Type } 1 \\
\text { Type } 2\end{array}$ & $\begin{array}{l}\cdots \\
\cdots \\
\cdots\end{array}$ & $\begin{array}{l}\cdots \\
\cdots \\
\cdots\end{array}$ & $\begin{array}{l}12 \\
18 \\
10\end{array}$ & $\begin{array}{r}11 \\
8 \\
10\end{array}$ & $\begin{array}{r}1 \\
10 \\
0\end{array}$ \\
\hline Total & $\ldots$ & $\ldots$ & 40 & 29 & 11 \\
\hline
\end{tabular}

Table IV shows the number of valves studied as regards obstruction and incompetence in these 40 patients. The mitral valves are subdivided into those inserted earlier using the original technique of fashioning the valves (type 1) and those later cases with looser cusps (type 2) (Table II).

Thirty-one patients were not studied postoperatively, some because of the patient's refusal, others because of long distances involved and, in a few instances, 
because of severe disability such as hemiplegia. Four mitral and three aortic patients died subsequent to operation and, except for two, were not studied postoperatively.

The data obtained were right atrial, right ventricular, left atrial, left ventricular, and aortic pressures, with simultaneously measured gradients across the prosthetic valves, aortic and right ventricular oxygen saturation values, cardiac output by indicator dilution, and regurgitant flow measured by dye curves (Lacy, Goodson, Wheeler, and Newman, 1959) and estimated by cineangiography. The ejection fraction was measured from the cineangiogram (Greene, Carlisle, Grant, and Bunnell, 1967).

\section{RESULTS}

\section{AORTIC VALVES}

INCOMPETENT VALVES Of the 12 prostheses investigated, one was found to be incompetent. This was a patient with moderate reflux on angiogram and $15 \%$ reflux on dye curves. She had an early diastolic murmur and her aortic and left ventricular pressures were $170 / 80$ and 200/3-8 respectively. She remains incapacitated by dyspnoea.

COMPETENT VALVES Eleven valves were found to be completely or almost completely competent and their data are presented below. In one preoperative and one postoperative study the left ventricle was not entered and the data are incomplete.

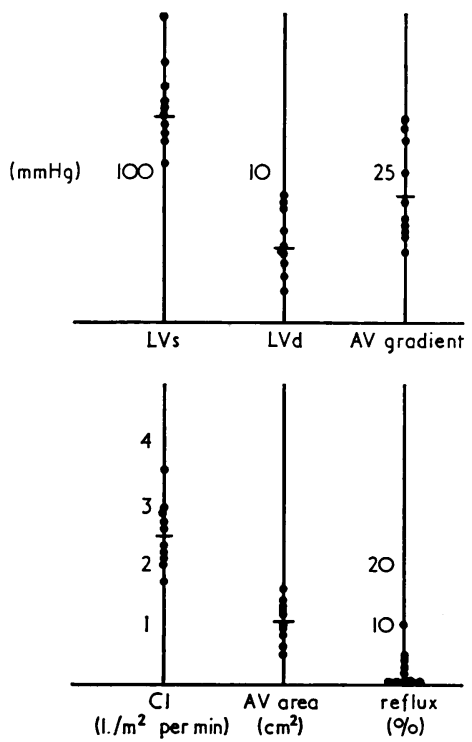

FIG. 2. Haemodynamic data six months after aortic valve replacement with fascial prosthesis. Competent prostheses only included.
Figure 2 shows the haemodynamic findings and Fig. 3 a comparison with preoperative catheter studies.
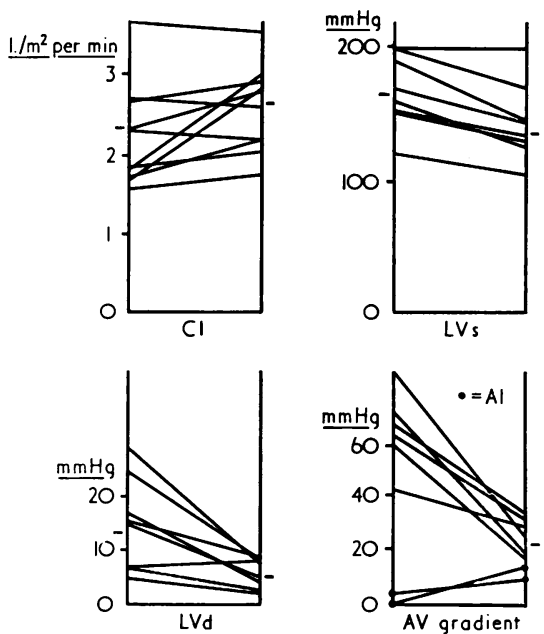

FIG. 3. Comparison of pre-and postoperative haemodynamic data in patients undergoing aortic valve replacement.

Pressure gradient Mean resting systolic gradients measured by planimetry averaged 24 with a range of 10 to $35 \mathrm{mmHg}$. In all except two cases who had gross aortic regurgitation before surgery the pressure gradient showed a considerable fall from the preoperative values of 42 to $98 \mathrm{mmHg}$.

Valve area An estimate of equivalent aortic valve area, using the Gorlin equation (Gorlin and Gorlin, 1951), gave a range of 0.4 to $1.4 \mathrm{~cm}^{2}$ with a mean of $1.0 \mathrm{~cm}^{2}$. There was some relationship between this area and the internal diameter of the titanium frame used in constructing the valve (Fig. 6). The smallest size of frame $(18 \mathrm{~mm}$ diameter) gave a result corresponding to moderate aortic stenosis.

Left ventricular pressure The left ventricular enddiastolic pressure ranged from 3 to 8 with a mean of $5 \mathrm{mmHg}$. It is interesting that all cases had normal left ventricular diastolic pressures postoperatively where half or more had elevated pressures preoperatively. Left ventricular systolic pressures showed a fall in all but one case and averaged $140 \mathrm{mmHg}$ with a range of 105 to 200 $\mathrm{mmHg}$.

The rate of rise of pressure during isovolumetric contraction (dp/dt) averaged $1,343 \mathrm{mmHg} / \mathrm{sec}$ with a range of 1,080 to 1,900 . These values are 
much closer to normal than in the case of mitral valve replacement.

Aortic pressures In view of the differing types of aortic lesion treated by replacement no consistent pattern of change was to be expected. Postoperatively aortic pulse pressure averaged 46 $\mathrm{mmHg}$ with a range of 30 to $85 \mathrm{mmHg}$, and mean pressure was $100 \mathrm{mmHg}$ with a range of 80 to $120 \mathrm{mmHg}$.

Cardiac output Although all but two cases with reduced cardiac output showed a rise after valve replacement the postoperative values were below normal values in general, though less so than after mitral replacement. The mean value was 2.50 $1 . / \mathrm{m}^{2} / \mathrm{min}$ with a range of 1.70 to $3.641 . / \mathrm{m}^{2} / \mathrm{min}$. Regurgitant fraction Values for regurgitant fraction obtained from dye curves were all below $5 \%$ with one exception where $10 \%$ was recorded though reflux was scarcely visible on angiogram.

Supravalvular aortogram These showed no or minimal reflux at the valve. In most cases a negative jet was visible during systolic ejection showing axial flow through the valve.

CONCLUSION In the case of the 11 competent valves studied a fascial prosthesis appeared to be satisfactory, with good left ventricular function and acceptably low valve gradients except in a few cases with the smallest size of valve frame.

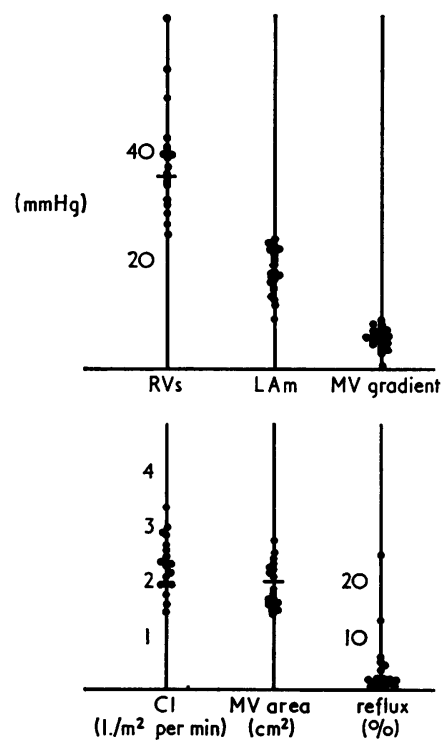

FIG. 4. Haemodynamic data six months after mitral valve replacement with fascial prosthesis. Competent prostheses only included.

\section{MITRAL PROSTHESES}

INCOMPETENT VALVES Of the 18 type 1 prostheses 10 , and of the type 2 none, were found to be more $\frac{\bar{N}}{\mathrm{~N}}$ than trivially incompetent at catheterization. All $\overparen{\nabla}$ of these patients had mitral systolic murmurs. The $\varrho$ degree of incompetence varied from mild $(25 \%$ ळ reflux) to gross ( $70 \%$ reflux). Their left atrial $\vec{\circ}$ pressures ranged from $12 / 6$ to $50 / 12$, and right ventricular systolic pressures from 30 to $90 \mathrm{mmHg}$. $\vec{\omega}$ Despite the regurgitation three of the 10 claimed to be good symptomatically, two were fair, and $x$ five were severely incapacitated, of whom four $N_{\infty}^{N}$ had the prosthesis replaced at a later date.

COMPETENT VALVES Eight type 1 and 10 type $2 \vec{g}$ mitral valves were found to be completely, or 0 almost completely, competent and their data are therefore presented in more detail.

Figure 4 shows the haemodynamic data in these patients and Fig. 5 the comparison with pre- $\frac{O}{J}$ operative catheter studies.
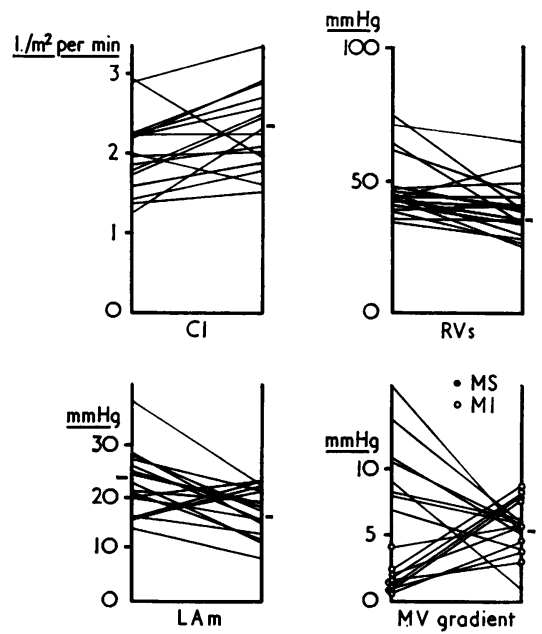

FIG. 5. Comparison of pre-and postoperative haemodynamic data in patients undergoing mitral valve replacement.

Pressure gradient Mean diastolic gradients by $N$ planimetry over several cardiac cycles averaged $5.2 \mathrm{mmHg}$ with a range of 1.2 to $8.1 \mathrm{mmHg}$.

Valve area An estimate of equivalent mitral 6 valve area, using the Gorlin equation, ranged from 1.2 to $2.8 \mathrm{~cm}^{2}$. There was some relationship ? between this area and the size of prosthesis used in fashioning the valve. The smallest size of frame gave a result corresponding to moderately severe mitral stenosis (Fig. 6).

Left atrial pressures Pressures ranged from 14/5 to $40 / 15$ with a mean of $17 \mathrm{mmHg}$. With four 

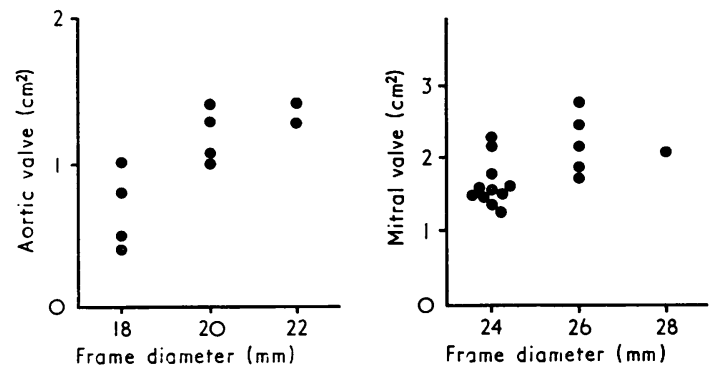

FIG. 6. Relation between internal diameter of supporting frame used in construction of aortic and mitral valves and calculated valve area postoperatively (Gorlin formula).

exceptions in patients who had gross reflux preoperatively this represented a considerable improvement by comparison with preoperative values. It does emphasize the fact, however, that even well functioning prosthetic valves do not approach the normal valve in function.

Left ventricular pressures The left ventricular enddiastolic pressures were nearly all abnormal postoperatively, ranging from 1 to $20 \mathrm{mmHg}$ with a mean of 9. The rate of rise of pressure during isovolumetric contraction, $\mathrm{dp} / \mathrm{dt}$, was depressed, averaging $1,280 \mathrm{mmHg} / \mathrm{sec}$ with a range of 950 to $2,500 \mathrm{mmHg} / \mathrm{sec}$.

Right ventricular systolic pressure This showed a decrease from preoperative levels but with a mean value of $40 \mathrm{mmHg}$ and range 25 to 70 they remained well above the normal values.

Cardiac output The cardiac index averaged 2.25 (range 1.40 to 3.30 ) against normal values of 3.00 to $3.751 . / \mathrm{m}^{2} / \mathrm{min}$. On the whole, however, they showed some improvement from preoperative values.

Regurgitant fraction This was estimated by the method of Lacy et al. (1959) as an attempt to quantitate the degree of reflux. Since all incompetent valves had been excluded from this study, the values (representing the ratio of area of backward to forward dilution curves expressed as a \%) are all low or zero.

Left ventricular angiogram The results correlated completely with the dye dilution results. Only minimal regurgitation was visible in a few of these patients.

Left ventricular ejection fraction Ejection fraction measured by the method of Greene et al. (1967) from the single-plane left ventricular cineangiogram averaged $71 \%$ with a range of 52 to $90 \%$.

CONCLUSION In these 18 patients with competent fascial mitral prostheses resting valve gradients were acceptably low in the majority and compare well with those measured in other prostheses (Table V). Moderate haemodynamic improvements were recorded compared with preoperative values. Left ventricular function does not return to normal despite the insertion of a competent prosthesis, and some degree of obstruction to flow remains. Cardiac output, left ventricular diastolic pressure, and $\mathrm{dp} / \mathrm{dt}$ remain abnormal.

INCOMPETENT MITRAL VALVES Ten of the 28 mitral valves studied were found to be incompetent. In two cases the leak was perivalvular, resulting from partial detachment of the prosthesis from the valve ring. Of the remaining eight, all were type 1 mitral valves and none was type 2 . It was possible to examine five of these eight valves subsequently. All showed the changes of sclerosis and cusp thickening and retraction described by others (Silver and Trimble, 1971 ; McEnany et al., 1972). The question remains whether all the mitral

T A B LE V

RESTING PRESSURE GRADIENTS IN PATIENTS WITH PROSTHETIC VALVES

\begin{tabular}{|c|c|c|c|c|c|}
\hline & Cype & Author & No. of Cases & Mean Gradient (mmHg) & Range \\
\hline $\begin{array}{c}\text { Mitral valve } \\
\text { Starr Edwards } \\
\text {," ", ", } \\
\text {," } \\
\text { Fascia lata", }\end{array}$ & $\begin{array}{l}61200 \\
6300 \\
6000 \\
6120(2 \mathrm{M}) \\
6300(2 \mathrm{M}+3 \mathrm{M}) \\
6000(3+4 \mathrm{M})\end{array}$ & $\begin{array}{l}\text { Hodam et al. (1969) } \\
\text { Mörow "̈t al. (19̈64) } \\
\text { Glancy et al. (1969) } \\
\text { Present dätä ", }\end{array}$ & $\begin{array}{l}12 \\
12 \\
14 \\
28 \\
12 \\
18\end{array}$ & $\begin{array}{l}7 \cdot 4 \\
9 \cdot 4 \\
4 \cdot 7 \\
7 \cdot 0 \\
2 \cdot 6 \\
5 \cdot 2\end{array}$ & $\begin{array}{l}0-13 \\
5 \cdot 6-12 \cdot 5 \\
2 \cdot 0-8 \cdot 0 \\
2 \cdot 0-20 \\
0-5 \cdot 2 \\
1 \cdot 2-8 \cdot 1\end{array}$ \\
\hline $\begin{array}{c}\text { Aortic valve } \\
\text { Starr Edwards } \\
\text {," ," } \\
\text { Björk-Shiley } \\
\text { Kay-Shiley } \\
\text { Fascia lata }\end{array}$ & $\begin{array}{l}1000 \\
2300\end{array}$ & 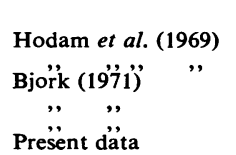 & $\begin{array}{r}32 \\
12 \\
46 \\
41 \\
34 \\
8\end{array}$ & $\begin{array}{l}21 \\
41 \\
17 \cdot 5 \\
11 \cdot 8 \\
27 \\
24\end{array}$ & $\begin{array}{r}0-35 \\
17-68 \\
0-47 \\
0-37 \\
9-61 \\
10-35\end{array}$ \\
\hline
\end{tabular}


prostheses will inevitably undergo this degenerative change or whether some haemodynamic factor predisposed these particular valves to be affected. The eight patients with leaking prostheses have therefore been compared with those with nonleaking prostheses in an attempt to find any common factor which might be implicated. The comparison shows that:

(a) valve failure was confined to the type 1 . Loose cusp tissue tended to prevent the development of incompetence ;

(b) there was no significant difference between the patients with leaking and those with competent valves as regards preoperative parameters (cardiac rhythm and output, left ventricular and left atrial pressures, electrocardiogram), or in postoperative left ventricular size as measured from cineangiography, or left ventricular ejection fraction ;

(c) those with leaking valves had higher valve gradients (average $7 \cdot 1 \mathrm{mmHg}$ ) than those with competent valves, attributable to the regurgitation producing relative stenosis of the prosthesis;

(d) the pattern of left ventricular diastolic filling shown by the flow of blood into the opacified ventricle during cineangiography was different in the leaking group than in the competent group.

In general three types of filling were seen in the whole group of patients (Fig. 7):
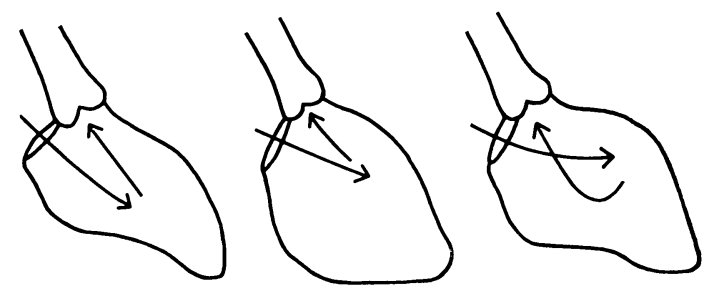

FIG. 7. Three types of flow pattern through the left ventricle seen in patients with fascia lata mitral prostheses. Six out of eight patients with leaking prostheses showed type 3.

(1) a filling wave passing directly towards the apex in long narrow ventricles and approximating to the pattern in normal valves;

(2) in broad ventricles with large volumes a filling wave passing anteriorly followed by aortic ejection, leaving a large volume of blood in the inflow portion of the ventricle poorly mixed ;

(3) filling towards the anterior ventricular wall with some bulging of the wall followed during systole by a circular downward and backward movement of blood towards the posterior cusp of the mitral valve. Systolic contraction appeared asymmetrical with more vigorous contraction in the distended anterior wall of the ventricle.

In types 2 and 3 the plane of the mitral prostheses appears to be relatively acutely angled to that of the aortic root instead of nearly parallel with it, as in the case of the normal valve, and inflowing blood came directly under the aortic root instead of through what would normally be the inflow tract of the ventricle. Six of the eight leaking valves had type 3 filling whereas only two of 15 competent valves showed this pattern.

\section{DISCUSSION}

The findings indicate that haemodynamically the performance of both aortic and mitral fascia lata valves at six months is at least as good as that of any of the mechanical prostheses.

The aortic valves were competent, with one cxception, and offered an acceptably low resistance to ejection compared with mechanical prostheses (Table V). Even with the central orifice, however, there was a significant transvalvular pressure gradient and it seems important to fit the largest possible size of frame. Angiograms show how relatively narrow the effective orifice size is in comparison with the ring diameter. Cardiac output remains slightly subnormal in these patients and left ventricular function was good with end diastolic pressures within the normal range.

The mitral valves were less satisfactory on several counts. There was a high rate of incompetence, although this was confined entirely to the earlier type 1 valve, and it is possible that the modification with looser cusps may, in the long term, prove more reliable.

Those valves which were competent had an average diastolic gradient of $5.2 \mathrm{mmHg}$ with a range of 1.2 to $8.1 \mathrm{mmHg}$. This is perhaps surprising in a central orifice valve but is confirmed by the delayed left atrial emptying on angiogram and is probably connected with the stiffer than normal nature of the cusp material and the relatively small effective orifice size in relation to ring diameter. Replacement of a damaged mitral valve with a competent prosthesis did not return left ventricular function to normal. Cardiac output remained low and left ventricular diastolic pressure and $\mathrm{dp} / \mathrm{dt}$ in most cases remained abnormal. 
Of 14 patients with competent valves in whom complete data were available, six had large left ventricles, high end diastolic pressures, and low ejection fractions, while eight had small ventricles and low diastolic pressures. Both groups, however, had low cardiac indices and mixed venous oxygen saturations. To what extent this is the result of purely myocardial impairment rather than valve function is uncertain; all the valves were competent but the mode of closure of the valve is abnormal and it is possible that this in itself, implying as it does significant systolic reversal of flow through the ventricle, may affect ventricular function adversely.

Valve function is quite abnormal in the fascial mitral valve. The important factor of ring-vortex formation behind the two cusps of the normal valve which cause presystolic.closure (Bellhouse, 1972) and the papillary muscle-chordal apparatus which completes closure are absent, and closure is by ventricular contraction. This was evident angiographically with early systolic repulsion of the mitral cusps and sometimes a slight early systolic puff of dye through the centre of the valve. The cusps of the prosthetic mitral valve are therefore subject to considerably more stress than the cusps of the normal valve. Perhaps an additional factor suggested by the present study is the alignment of the prosthesis relative to the ventricular cavity. Normally the aortic cusp of the mitral valve acts as a baffle to direct blood into the inflow tract of the ventricle. In many of the fascia lata valves, and particularly in those showing incompetence, the inflow of blood was directed against the anterior wall of the left ventricle.

This difference may point to the conclusion that the pathological changes leading to valve failure occur not in all valves but in those in which haemodynamic stresses of a particular kind occur, perhaps associated with a particular ventricular shape or with the alignment of the valve orifice in relation to inflow and outflow tracts of the ventricle. These factors could be much more important in a cusped valve than in a simple ballvalve mechanism. The relative success of fascial valves in the aortic position, where they are anatomically more similar to the normal valve, is additional evidence for this view. Possibly a tissue valve for the mitral position could be designed to overcome some of these objections, and the design proposed by Yacoub, Towers, and Somerville (1972) appears to offer both retention of some cusp closure by vortex formation and the possibility of direction of inflow blood into the inflow tract of the ventricle.
The long-term outlook for these valves remains in doubt. Our experience contrasts with that of Schwartz et al. (1971), who studied 19 aortic valves, four to 10 months postoperatively. They found aortic regurgitation in 16 , of which 14 were mild and two marked. They also found moderate or severe insufficiency in nine out of $11 \mathrm{mitral}$ valves and in four out of five tricuspid valves. They concluded that the use of the valve was inadvisable because of the development of regurgitation. Valve gradients were acceptably low and similar to those recorded here.

Our more favourable experience with the type 2 mitral prosthesis suggests that it may be premature to reject the autologous valve with its considerable other advantages. If the incidence of serious regurgitation can be reduced to a low figure it may be acceptable, since valve regurgitation is a remediable and therefore less serious complication than a cerebral embolism or many cases of sudden mechanical failure in totally artificial valves. The results must be viewed against the background of considerable mortality and morbidity of Starr Edwards valves and the continuing nuisance and hazard of permanent anticoagulant therapy.

\section{REFERENCES}

Barclay, R. S., Reid, J. M., Stevenson, J. G., Welsh, T. M., and McSwan, N. (1972). Long-term follow-up of mitral valve replacement with Starr-Edwards prosthesis. Brit. Heart J., 34, 129.

Bellhouse, B. J. (1972). Fluid mechanics of a model mitral valve and left ventricle. Cardiovasc. Res., 6, 199.

Björk, V. O. (1971). Aortic valve replacement with the Bjork-Shiley tilting disc valve prosthesis. Brit. Heart $J ., 33$, supplement p. 42.

Duvoisin, G. E., Wallace, R. B., Ellis, F. H., Anderson, M. W., and McGoon, D. C. (1968). Results of cardiacvalve replacement. Circulation, 38, Suppl. II, 75.

Gerbode, F. (ed.) (1970). Proc. First Internat. Workshop on Tissue Valves, p. 18. Suppl. to Ann. Surg., 172, No. 1.

Glancy, D. L., O'Brien, K. P., Reis, R. L., Epstein, S. E., and Morrow, A. G. (1969). Haemodynamic studies in patients with $2 \mathrm{M}$ and $3 \mathrm{M}$ Starr-Edwards prostheses: evidence of obstruction to left atrial emptying. Circulation, 39, Suppl. I, p. 113.

Gonzalez-Lavin, L., Geens, M., and Ross, D. N. (1970). Mitral valve replacement with autologous tissue. Arch. Surg., 101, 760.

_ in combined aortic and mitral valve replacement. Ann. thorac. Surg., 12, 236.

Gorlin, R., and Gorlin, S. G. (1951). Hydraulic formula for calculation of the area of the stenotic mitral valve, other cardiac valves, and central circulatory shunts. Amer. Heart J., 41, 1. 
Greene, D. G., Carlisle, R., Grant, C., and Bunnell, I. L. (1967). Estimation of left ventricular volume by oneplane cineangiography. Circulation, 35, 61 .

Hodam, R., Starr, A., Herr, R. and Pierie, W. R. (1969). Early clinical experience with cloth-covered valvular prostheses. Ann. Surg., 170, 471.

Ionescu, M. I., Ross, D. N., Deac, R., Grimshaw, V. A., Taylor, S. H., Whitaker, W., and Wooler, G. H. (1970a). Autologous fascia lata for heart valve replacement. Thorax, 25, 46.

- Wooler, G. H., Deac, R., and Ray D. (1970b). Replacement of heart valves with autologous fascia lata. Brit. J. Surg., 57, 437.

Lacy, W. W., Goodson, W. H., Wheeler, W. G., and Newman, E. V. (1959). Theoretical and practical requirements for the valid measurement by indicator-dilution of regurgitant flow across incompetent valves. Circulat. Res., 7, 454.

McEnany, M. T., Ross, D. N., and Yates, A. K. (1972). Valve failure in 72 frame-supported autologous fascia lata mitral valves. J. thorac. cardiovasc. Surg., 63, 199.

Morrow, A. G., Clark, W. D., Harrison, D. C., and Braunwald, E. (1964). Prosthetic replacement of the mitral valve: operative methods and the results of preoperative and postoperative haemodynamic assessments. Circulation, 29, Suppl. I, p. 2.
Rees, J. R., Miscall, B. G., Holswade, G. R., Castandea, A., and Lillehei, C. W. (1970). Late results of valve replacement. Surgery, 67, 141.

Ross, D. N., Gonzalez-Lavin, L., and Dalichau, H. (1972). A two-year experience with supported autologous fascia lata for heart valve replacement. Ann. thorac. Surg., 13, 97.

Schwartz, L., Trimble, A., Adelman, A., Aldridge, H., and Morch, J. (1971). Haemodynamic follow-up of autologous fascia lata valves. Circulation, 54, Suppl. II, p. 223.

Senning, A. (1967). Fascia lata replacement of aortic valves. J. thorac. cardiovasc. Surg., 54, 465.

Silver, M. D., and Trimble, A. S. (1971). Morphology of fascia lata heart valve prostheses. Circulation, 54, Suppl. II, p. 26.

Yacoub, M., Towers, M., and Somerville, W. (1972). Mitral valve replacement using fresh 'unstented' semilunar valve homografts. (abstract). Brit. Heart J., 34, 207. 